U.S. Department of Agriculture

Animal \& Plant Health Inspection Service

Wildilife Services

February 2018

Wildlife Damage Management Technical Series

\title{
Mute Swans
}

David R. Marks

District Supervisor

USDA-APHIS Wildlife Services

Urbandale, lowa

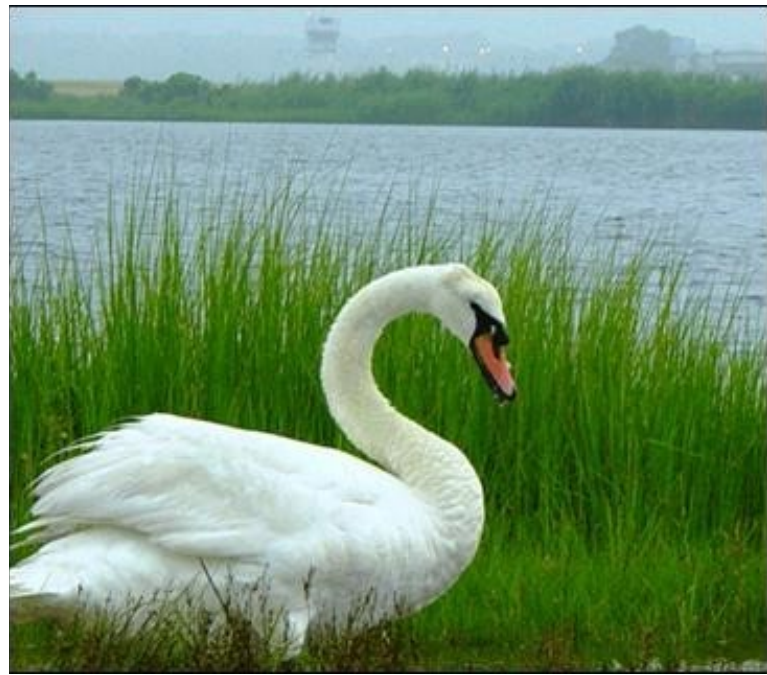

Figure 1. Adult mute swan (Cygnus olor).

\section{Human-Wildlife Conflicts}

Mute swans (Cygnus olor, Figure 1) are an invasive species originally brought to the United States in the late 19th and early 20th centuries for ornamental ponds and lakes, zoos and aviculture collections. Original populations were located in northeastern states along the Hudson Valley but have since expanded to several Midwestern states and portions of the western U.S. and Canada.

Mute swan damage includes competing with native waterfowl, destroying native plants, spreading disease, and colliding with aircraft. They are also considered a nuisance in some areas due to their abundant fecal droppings and aggressiveness towards people.

\section{Natural Resources}

Mute swans can impact ecosystems by foraging on native plants and competing with native species for food and habitat. Mute swans forage primarily on submerged aquatic vegetation, and each swan consumes 4 to 8 pounds of vegetation per day. While feeding, mute swans use their feet to expose plant shoots and roots for foraging, and to help dislodge food for cygnets (i.e., young swans). This damages aquatic substrates and vegetation surrounding preferred foods. Mute swans typically consume less than 50 percent of what they remove. Results from one study showed their diet overlaps considerably with many native 
waterfowl species that overwinter in the lower Great Lakes or temporarily use the area during migration.

Mute swans are known for their highly territorial behavior during their breeding season, and may compete with native wildlife for space and associated resources. Of particular concern are potential impacts on threatened and endangered species. During the breeding season, mute swans sometimes displace other native waterfowl from preferred nesting locations, and may kill adult and juvenile ducks and geese (Figure 2). During one incident in Maryland, a large molting flock of mute swans caused a colony of least terns (Sterna antillarum) and black skimmers (Rynchops niger) to abandon a nesting colony by trampling nests, eggs, and chicks. The mute swans also displaced nesting common terns (Sterna hirundo). In 2011 in Michigan, a mute swan nest was found in the middle of a black tern (Chlidonias niger) colony that had previously supported approximately 54 black terns in 2009 . Only a few black tern nests remained, approximately 30 to 40 feet away from the swan nest.

\section{Agriculture}

In some portions of the world, mute swans damage agricultural crops, such as wheat and oilseed rape. In the U.S., however, incidents of swan damage to crops are rare.

Mute swans may serve as vectors or reservoirs for diseases of significance to agriculture, such as Newcastle disease and avian influenza. A 2014 study showed that 60 percent and 45 percent of the mute swans sampled had been exposed to Newcastle disease virus and avian influenza virus, respectively.

\section{Human Health and Safety}

While the transmission of diseases or parasites from waterfowl to people has not been well documented, various studies indicate that the potential exists. In worst case scenarios, infections may be life-threatening for immunocompromised people. Diseases that potentially may be transmitted through mute swan feces to people include swimmer's itch, salmonellosis, and E. coli infections. However, scientists at the Centers for Disease Control and Prevention estimate the risk of such infections is low. Costs associated with disease issues and mute swans can be high and include the following:

- $\quad$ testing of water for coliform bacteria

- $\quad$ regularly cleaning feces from beaches and other recreational areas

- $\quad$ lost revenue associated with recreational sites that are temporarily closed because of fecal contamination

- $\quad$ consultation with public health officials

- implementing nonlethal and lethal mute swan damage management methods

In addition to disease issues, mute swans also threaten air safety. Bird strikes usually kill birds and can damage aircraft, disrupt airport operations, and erode public confidence in the safety of air travel. Mute swan collisions with aircraft not only risk human safety, but also result in expensive damage to aircraft, loss of aircraft due to repairs, and monetary losses due to flight cancellations and delays. In the U.S. from 1994 to 2011, there were eight reported mute swan bird strikes. Although this number is low compared to other species, the size of mute swans makes them particularly hazardous to aircraft.

In areas with high numbers of mute swans, attacks on people and pets have become more frequent. Mute swans defend their nests, nesting areas, and young from any

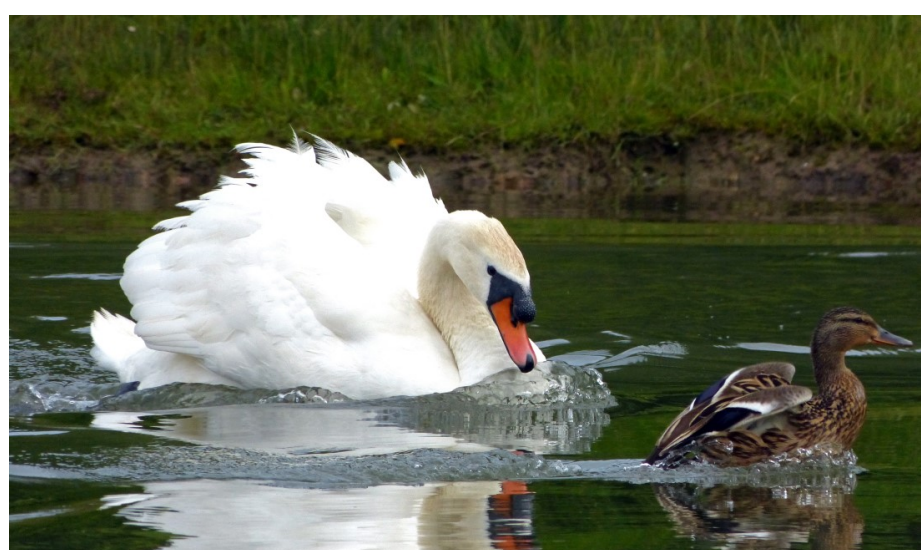

Figure 2. Mute swan showing aggression toward a mallard. 
perceived threats, including people and pets. Birds that are fed by people may become aggressive in seeking food. Most of the aggressive behavior involves displaying dominant postures and making hissing noises, without making physical contact (called bluffing). However, mute swans are capable of inflicting bruises, sprains and bone fractures. In at least one case in Illinois, a mute swan attack resulted in a human fatality. A man in a kayak ventured too close to a mute swan nest; the swan attacked and caused the man to capsize the kayak. The man was not wearing a personal floatation device and witnesses reported the swan continued to attack as the man tried to keep his head above water.

\section{Nuisance}

Most conflicts between mute swans and people affect people's enjoyment of recreational sites or activities. People often cannot use and enjoy their own property, public parks and other areas because of aggressive swans or the accumulation of swan feces. Costs associated with mute swan nuisance problems include labor and disinfectants to clean and sanitize areas, loss of property use and resale value, loss of aesthetic value of aquatic vegetation in areas where mute swans nest, loss of customers or visitors fearful of swimming in waters with swan feces or of being attacked by aggressive swans and implementation of wildlife management methods.

\section{Damage Identification}

Most mute swan damage is difficult to attribute to the species unless the birds are actually observed causing the damage. For instance, competition with other waterfowl for breeding or food resources may not be readily seen.

Observable mute swan damage includes destruction of submerged and emergent aquatic vegetation. Mute swans typically consume only about 50 percent of the material they uproot or damage during feeding, therefore, remnant vegetation is often floating in areas where mute swans have fed. Although damage to submerged aquatic vegetation may be difficult to assess because it occurs

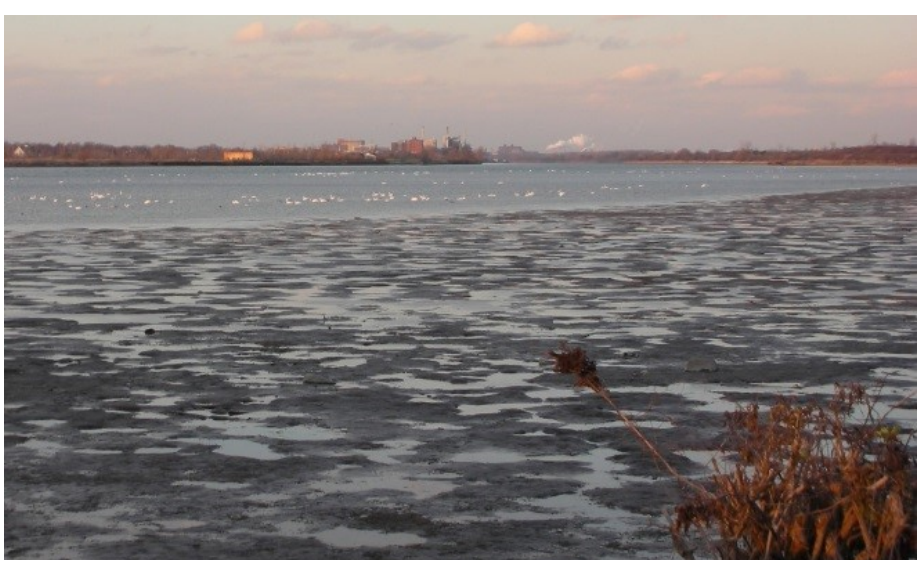

Figure 3. Area completely denuded of submerged aquatic vegetation by mute swans feeding in the area along the Detroit River, Michigan. Area exposed as water level dropped.

underwater, it may become apparent as remnant vegetation accumulates along shorelines and beaches. Damage also may become visible during periods of lower water levels (Figure 3).

Damage to emergent vegetation typically occurs during the breeding season when swans are building their nests.

Plants are used for the nest itself, and often large mats of uprooted vegetation can be found surrounding the nests (Figure 4).

Mute swan feces can impact water quality, and land areas surrounding ponds and lakes, such as parks, beaches, and lawns.

\section{Management Methods}

The most effective way to resolve wildlife damage is to integrate the use of several management methods either simultaneously or sequentially. The philosophy behind integrated pest management (IPM) is to implement the best combination of effective management methods in a cost-effective manner while minimizing the potentially harmful effects on people, target and non-target species, and the environment. IPM may incorporate cultural practices (e.g., no feeding policies), habitat modification (e.g., exclusion), animal behavior modification (e.g., 


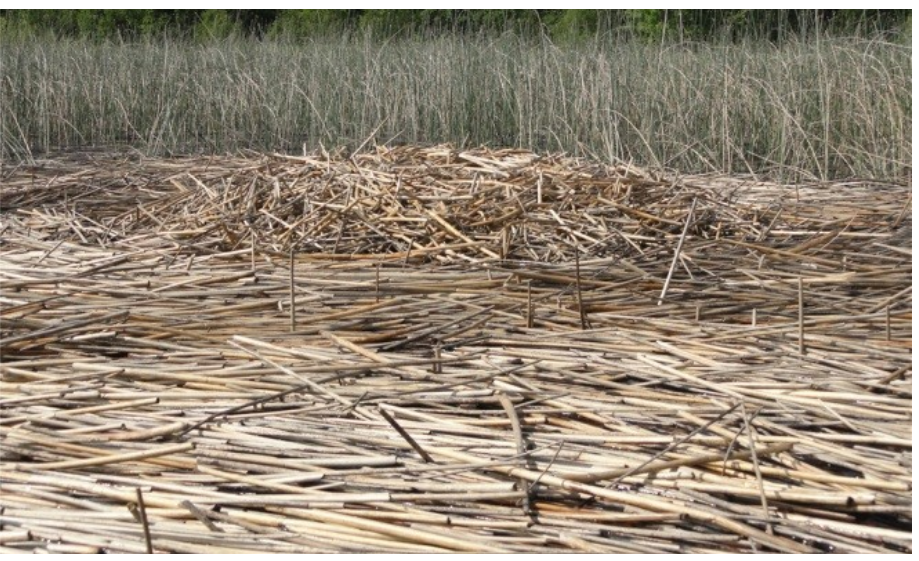

Figure 4. Mute swan nest built of bulrushes surrounded by a large floating mat of ripped-up vegetation.

frightening devices), nonlethal or lethal removal of individual animals, local population reduction, or any combination of these. The course of action depends on the circumstances of the specific damage problem. Consider the biology and behavior of the damaging species and other factors when developing an IPM strategy. The recommended strategy may include any combination of preventive and corrective actions.

\section{Preventive damage management applies IPM strategies} before damage occurs, based on historical problems and data. Most preventive management techniques are nonlethal methods, and are most commonly applied by the resource owner or manager. An example is installing and maintaining a fence and/or overhead wire grid system to reduce mute swan access to a retention pond.

Corrective damage management uses IPM strategies to stop or reduce current conflicts. Both nonlethal and lethal methods may be used for corrective damage management. Examples include using pyrotechnics or border collies to chase away birds, removing breeding pairs of mute swans, or oiling eggs.

\section{Habitat Modification}

Habitat modification can include planting vegetation that is unpalatable to wildlife or altering the physical habitat. Fences, hedges, shrubs, boulders, etc. can be placed at shorelines to impede mute swan movements between water and land. This method is less effective with mute swans than with other waterfowl species, such as Canada geese (Branta canadensis), because mute swans do not feed on land and do not often loaf on land.

Removing submerged aquatic vegetation (food source) and emergent vegetation (nesting materials) may also help. However, this impacts other wildlife and fish at the site, and may not be practical.

Mute swans require open water during winter months, therefore, removing aerators and allowing ponds to freeze will force the swans to leave. Again, this may impact other wildlife and fish at the site and may not be practical.

\section{Exclusion}

Like shrubs and boulders, adding electric fencing to a site may prevent swans from moving between the water and land. As with modifications to the shoreline habitat, this method is less effective with mute swans than with other waterfowl species. The use of electric fencing is usually limited to developed, nonrecreational sites because of potential risks to people or pets and may be prohibited in some areas. This method is not recommended for natural areas, such as wildlife refuges, given it could negatively impact nontarget species.

Other physical barriers and fencing, such as lawn furniture, vehicles, boats, snow fencing, plastic hazard fencing, metal wire fencing and multiple strand fencing, have been used to limit waterfowl movement, but have limited effectiveness. Fencing materials are most effective if the area to be protected can be completely enclosed and prevents birds from landing inside. Barriers are most effective when deterring small numbers of breeding mute swans and their flightless young from entering small portions of wetlands or waterways.

Mute swans may be excluded from small ponds using wire grids. Overhead wire grids are most effective and applicable to ponds less than 2 acres. Wire grids may be aesthetically unappealing to some people, and render a pond unusable for boating, swimming, fishing, and other recreational activities. Birds may also be deterred from using a pond by covering the pond's surface with 5-inch diameter floating balls. 


\section{Nest Treatment}

Egg oiling or puncturing can help reduce local mute swan populations. These methods involve locating the birds' nests and treating the eggs by either coating the eggs with corn oil or puncturing the eggshells, and then returning the treated eggs to the nest. The adult birds will continue to incubate the eggs and delay any attempts to re-nest. Generally, nests are visited more than once per breeding season to treat eggs. To ensure all eggs are treated, the nests must be treated during the incubation stage. If multiple swan nests are present at a particular site, they may have started nesting at different times and, therefore, some may be incubating while others are still laying or hatching. Treating swan nests is time and labor intensive and may not be the best method for quickly reducing mute swan populations. This method is primarily used with small, local swan populations in situations where the goal is to maintain the population at its current level.

Nest destruction is also used to reduce mute swan reproduction and discourage the use of a specific site. It involves locating the nests, destroying the eggs, and removing nest material from the site or dismantling nests and scattering the materials around the nest location. Birds may abandon the nest location and, depending on when the nest was destroyed during the breeding season, may attempt to re-nest at another site. This method is generally more useful for relocating problem birds than to reduce the population because of the tendency for birds to relocate and re-nest. Nest treatment may not be allowed or may require a special permit in some areas, so consult state wildlife agency regulations.

\section{Fertility Control}

None are available.

\section{Frightening Devices}

Hazing involves the use of visual, auditory and/or biological frightening stimuli to discourage birds from using an area. Birds hazed from one area where they are causing damage may simply move to another area and cause similar damage. Birds becoming accustomed to and eventually failing to respond to frightening devices (known as habituation) reduces the effectiveness of frightening devices. In general, hazing is not used to protect natural resources because it may negatively impact nontarget species.

\section{Visual}

Commonly used visual deterrents for birds include reflective tape, flags or similar objects. In Europe, high visibility tape has been effective at reducing mute swan damage to crops. However, the tool is impractical in many locations due to its cost and unattractive appearance on properties where it is used. Other studies have shown reflective tape to be ineffective and may be only a shortterm deterrent for mute swans.

Effigies depicting alligators, people and floating dead birds have deterred some bird use for short periods of time in small areas. Although scarecrows have been used to reduce migrant Canada goose use of agricultural fields in rural areas, they likely would not be as effective with mute swans since the birds have little fear of people. Like most frightening devices, the efficacy of scarecrows may be improved/extended through the occasional use of lethal methods (e.g., shooting,) to reinforce the threat associated with the frightening devices. Often, reinforcement with lethal methods is not an option in urban and suburban areas.

The effectiveness of lasers as a nonlethal bird deterrent has been tested on a number of species. In some studies, waterfowl showed avoidance reactions to lasers under low light conditions. In field tests, lasers were effective at dispersing large waterfowl flocks from a lake, with nearly no habituation to the technique. Wide-scale public use of lasers for dispersing swans is not recommended until additional research on the lasers' effectiveness and impacts to mute swans is completed.

\section{$\underline{\text { Audio }}$}

Pyrotechnics (i.e., screamer shells, bird bombs, and 12gauge cracker shells) are commonly used to disperse birds. Studies show the effectiveness of pyrotechnics can 
vary among different flocks of waterfowl. Some flocks in urban areas required continuous harassment throughout the day with frequent discharges of pyrotechnics. The waterfowl usually return to the area within hours. In Virginia, some flocks of Canada geese showed a quick response to pyrotechnics during winter months, suggesting migrant geese made up some or all of the flock. Mute swans are not a hunted species in the U.S., so pyrotechnics may be less effective with them versus migrant Canada geese. The effectiveness of pyrotechnics is partially dependent on the availability of alternative loafing and feeding areas. Because of safety and legal issues regarding their use, pyrotechnics may be inappropriate and prohibited in some areas.

Propane cannons are generally inappropriate for use in urban and suburban areas due to their repeated loud explosions which many people consider a nuisance and possible health threat (hearing damage). Although a propane cannon can be an effective dispersal tool for migrant waterfowl in agricultural settings, resident waterfowl in urban areas are more tolerant of noise and habituate to propane cannons relatively quickly. Since mute swans are not hunted in the U.S., propane cannons may not be effective.

\section{Biological}

Dogs are often used to harass waterfowl and keep them off of lawns and beaches. Around water, this technique appears to be most effective when the water body is smaller than two acres. Using dogs or other harassment techniques requires an ongoing financial and/or personnel commitment in order to be effective. When harassment with dogs ceases, the number of birds often returns to pretreatment levels. The use of dogs is not recommended when birds are molting or fledging, and are unable to fly.

\section{Repellents}

Methyl anthranilate (MA), an artificial grape flavoring food additive, is a registered repellent for use with waterfowl. It is marketed under a variety of trade names.
The effectiveness of MA appears to be mixed. One study reported that MA repelled Canada geese from grazing turf for four days. However, another study found it ineffective as a grazing repellent when applied at 20.2 pounds (label rate) and 60.5 pounds (triple the label rate) per acre.

MA is water-soluble, therefore moderate to heavy rain, daily watering or mowing render MA ineffective. More recent formulation strategies have been developed to address some of the problems associated with water solubility.

Instead of spraying it directly on a surface, MA may be applied more cost-effectively using a fog-producing machine. The fog drifts over the treated area and is irritating to exposed birds. It is not irritating to people. In contrast to the turf application, the manufacturer estimates that a one-gallon container of $40 \%$ MA concentrate for use in fogging applications is sufficient to treat up to 16 acres, depending on airflow. Several treatments spaced 1 to 4 days apart may be required to disperse nuisance birds. As with the turf application, it is likely that additional applications would be required to address conflicts with migrating or non-resident birds.

MA can be applied to temporary pools of water (e.g., water on airport runways or taxiways), but may not be directly applied to permanent water bodies, such as lakes, ponds, streams and rivers.

\section{Shooting}

Shooting mute swans can be highly effective for removing or reducing local populations and for reinforcing harassment activities. The shooter must be trained in the safe and effective use of firearms, and be able to distinguish between mute swans and other swan species. Shooting may not be allowed or may require a special permit in some areas, so consult state wildlife agency regulations. In addition, check local ordinances which may further restrict the use of firearms or require special permits and/or notification.

Shooting mute swans may not be a viable option, even if it is legal, simply due to public relations. Mute swans are a 
highly charismatic species. Often, people become accustomed to seeing the swans and enjoy viewing and even feeding them. Individuals that become emotionally attached to swans may consider any type of lethal management as inhumane.

As with any long-lived species that has multiple young every year, lethal removal of adult breeding mute swans is the most effective method of reducing populations. In addition, shooting a few individuals from a larger flock can reinforce the birds' fear of other harassment techniques.

A 12-gauge shotgun can be highly effective for shooting mute swans up to 50 to 75 yards, especially if several swans are to be removed in a quick manner. A mid-sized duck shot (Nos. 2 to 3 shot size) is recommend for head shots at stationary swans within 50 yards. A larger shot (BBB or T shot size) is recommended if swans are in flight or farther than 50 yards. Rifles are more effective for longer-range shots, and may have advantages if equipped with sound-suppressors. For removing single mute swans (e.g. aggressive male that has attacked people), a .22caliber rifle can be used at close range (less than 30 yards). Mid-size rifle calibers (e.g. .223 to .243) are recommended for shooting swans effectively up to 300 yards.

All ammunition used for removing mute swans should be non-toxic (no lead). A wide variety of steel or "heavier-thanlead" alloys are available for shotguns, and are required by law for use in areas with water. Although not necessarily required by law, it is highly recommended that non-toxic rifle bullets be used. To reduce the risk of ricochets on water, a highly frangible bullet is also recommended. Availability of highly-frangible, non-toxic rifle ammunition is currently limited to a few sources. The Varmint Grenade ${ }^{\circledR}$ by Barnes Bullets and the Controlled Chaos by Lehigh Defense, LLC are two options.

\section{Toxicants}

No toxicants are currently registered for use with mute swans.

\section{Trapping}

Birds may be captured with panel nets, rocket nets, drive traps, net guns, hoop nets or by hand. Mute swans typically molt from late July through August or early September. Molting mute swans do not typically loaf on land as Canada geese do, so capturing mute swans using panel nets or drive traps is less effective than with Canada geese. Rocket netting involves setting bait in an area that would be completely contained within the dimensions of a manually propelled net. The launching of the rocket net occurs too quickly for the birds to escape. Net guns are typically shoulder-mounted or hand-held. Rocket nets and net guns may be used anytime during the year. Again, consult the state wild life agency to determine if mute swans can be captured and, if so, whether they can be relocated and released. If relocation is not allowed, euthanize captured mute swans by one of the methods approved by the American Veterinary Medical Association.

\section{Handling}

Mute swans are large, strong birds and have little fear of people. Their strong wings are capable of inflicting bruises, sprains and other injuries to a handler. It is important to obtain proper training before handling any live swan to prevent injury to the handler and the bird.

\section{Relocation}

Check local and state regulations regarding the relocation of mute swans. Even if it is legal to relocate mute swans, it is not recommended because mute swans are a nonnative, invasive species. Relocating mute swans may result in damage to the area and further promote the spread of the species. If a mute swan must be relocated, it is recommended that it be surgically sterilized, rendered incapable of flight, and released on privately-owned land with the permission of the landowner.

\section{Euthanasia}

Conduct euthanasia of mute swans in a safe, humane and effective manner. Refer to the American Veterinary Medical Association's guidelines for recommended methods of euthanasia. 
Disposal

Euthanized mute swans must be buried, disposed of in landfills, or incinerated according to state or local regulations.

\section{Economics}

Little has been published on the economic costs associated with mute swan damage. The primary damage is the consumption of submerged aquatic vegetation, and destruction of habitat that is a valuable resource to other wildlife and fish. Mute swans also directly compete with other waterfowl for food and breeding habitat, and may act aggressively towards them, sometimes even killing them. These impacts are not easy to quantify. Furthermore, threats to human safety from aggressive swans, and disease risks due to fecal contamination, are subjective. Costs are incurred when sites must be cleaned or closed because of the presence of mute swans and/or the accumulation of mute swan feces.

Limited data exists on mute swan collisions with aircraft. In the U.S. from 1994 to 2011, there were eight reported mute swan strikes in the Federal Aviation Administration Wildlife Strike Database. There were no data recorded on the specific costs for damage incurred for any of these strikes. However, one strike report noted a flap skin was punctured and the plane was taken out of service for repair. Another strike report noted that a flock of five mute swans crossed the flight path immediately after takeoff and the pilot used evasive maneuvers to avoid colliding with the birds. Bird remains were subsequently recovered from the runway.

\section{Species Overview}

\section{Identification}

The mute swan is a member of the order Anseriformes and the family Anatidae which include ducks, geese and swans. They are one of six species in the genus Cygnus (swans). Two of these species, trumpeter swan (C. buccinators) and tundra swan (C. columbianus) are native to North America.

\section{Physical Description}

Adult mute swans are easy to recognize due to their large size, all white feathers and bright orange bills. Males typically weigh 20 to 25 pounds, and females are slightly smaller at 16 to 20 pounds. Wing spans typically are 7 to 8 feet for adult mute swans. They are distinguished from other white swans by their body size and bill color. Mute swans are larger than tundra swans which are typically around 13 to 15 pounds. However, body size cannot be used to distinguish mute swans from trumpeter swans. The best characteristic to use is bill color, as both tundra and trumpeter swans have black bills. Mute swans have a prominent black knob at the base of an orange bill (Figure 5).

Juveniles are more difficult to distinguish among the swan species. Body sizes vary depending on age and may overlap during the fledging stage. Juvenile swans of the three species vary in feather color as well, ranging from all gray to all white, with varying shades in between. Bill color can be similar among species, especially during the early stages of fledging when all three have gray-colored bills. As mute swans grow, bills begin to show shades of pink and eventually orange. The bills of tundra and trumpeter swans also may show shades of pink, but will eventually turn predominately black. The trained observer can use the shape of the bill to distinguish among the species of swans. The tundra and trumpeter swans have a more wedge-shaped bill compared to the mute swan's sloping bill and small knob. 


\section{Range}

Mute swans are native to Eurasia. They were introduced into the U.S. in the late $19^{\text {th }}$ and early $20^{\text {th }}$ centuries for ornamental ponds and lakes, zoos and aviculture collections. Original populations were located in northeastern states and feral breeding was believed to have first started among escaped birds in the lower Hudson Valley in 1910 and on Long Island in 1912.

Mute swans have since expanded their range to many eastern states, several Midwestern states and portions of the western U.S. and Canada (Figure 6). Established feral populations exist along the northern Atlantic coast, in the Great Lakes region, and the Pacific Northwest. Small localized populations of mute swans may be found in other locations throughout the U.S. due to intentional releases for aesthetic purposes.

\section{Voice and Sounds}

Although the name suggests mute swans make no sounds, this is not the case. Mute swan vocalizations are much quieter than other swans and do not carry far. They usually are limited to snorting or hissing when aggravated. Mute swans also emit a quiet trill or bugle to communicate with their mates or young. During flight, their large wings make a distinctive whistling who who sound that is relatively loud compared to their voice.
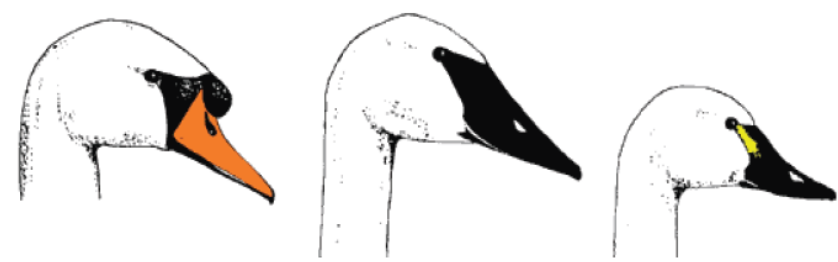

Mute Swan Trumpeter Swan Tundra Swan

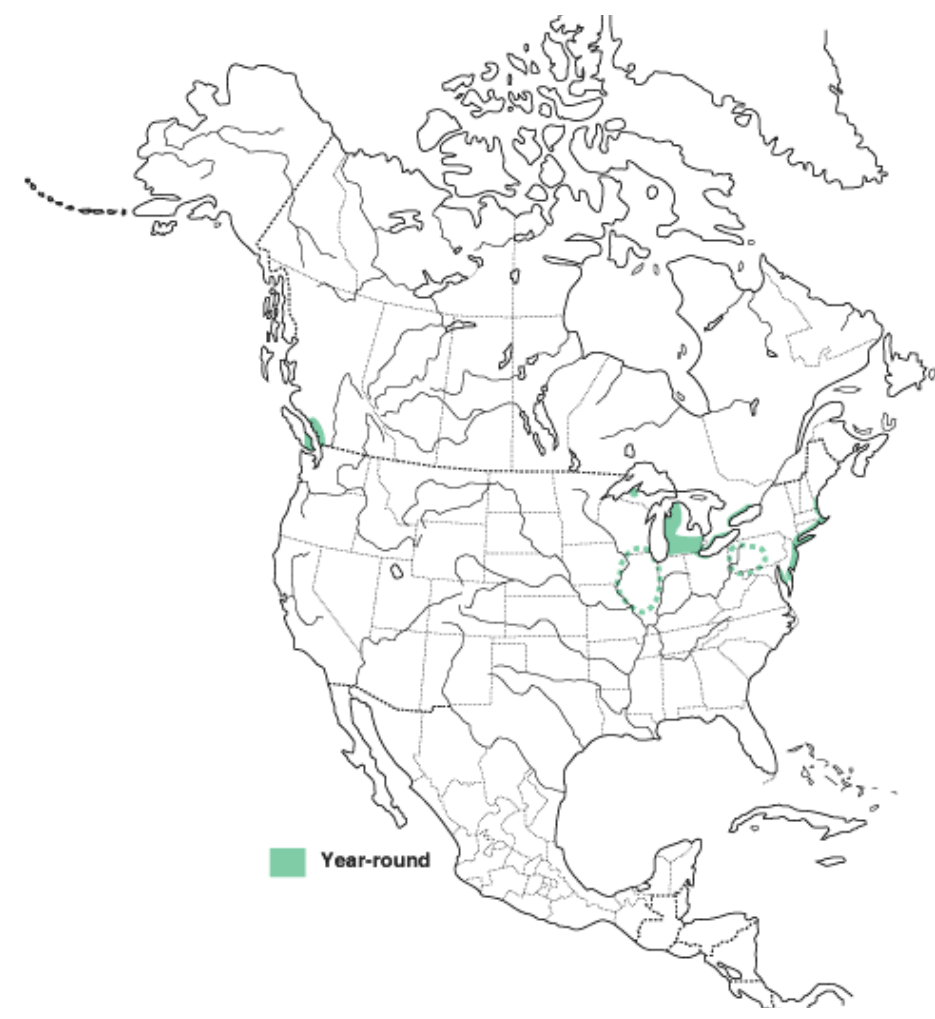

Figure 6. Range of mute swans.

\section{Tracks and Signs}

Due to their webbed feet, the tracks of mute swans are similar to other waterfowl, but much larger than those of ducks and geese. Track size is indistinguishable from trumpeter swans. Other mute swan signs include large fecal droppings, areas where aquatic vegetation has been removed and gathered into mounds for nests, and the presence of long, white flight feathers during the molting period.

\section{Reproduction}

Mute swans typically are monogamous, but have been known to separate and find new mates, particularly when breeding fails. A mute swan typically finds a new mate when its partner dies. The size of the breeding territory varies depending on the quality of the habitat, density of other breeding mute swan pairs, and the aggressiveness of that particular pair. Non-breeding mute swans do not

Figure 5. Bill colors and shapes of North American swans. 
establish territories, but rather congregate with each other throughout the year.

Mute swan nests are similar to Canada goose nests in construction and placement, but are about twice the size, averaging 5 to 6 feet in diameter and 1.5 to 2 feet high. Mute swans typically use emergent wetland vegetation to construct their nests. If emergent vegetation is lacking, they use other materials, such as sticks and floating debris. Nests usually are situated away from shorelines to minimize threats from predators. If emergent vegetation is lacking, mute swans may nest on shorelines or on islands.

Mute swans usually lay one egg every 2 days until the clutch is complete. The average clutch size varies in different regions, but an overall average is between 5 to 6 eggs. Most males are highly territorial during egg-laying, and some will help with incubation by sitting on the nest to allow the female to feed. Nesting periods vary among regions, but typically begin in March. Hatching occurs in May or June. Cygnets grow very quickly and are able to swim almost immediately after hatching once their down feathers dry (Figure 7). Adults protect cygnets from predators and other waterfowl (including other mute swans), and uproot vegetation for the cygnets to eat. By August, cygnets usually are similar in size to adults and have lost all their downy plumage.

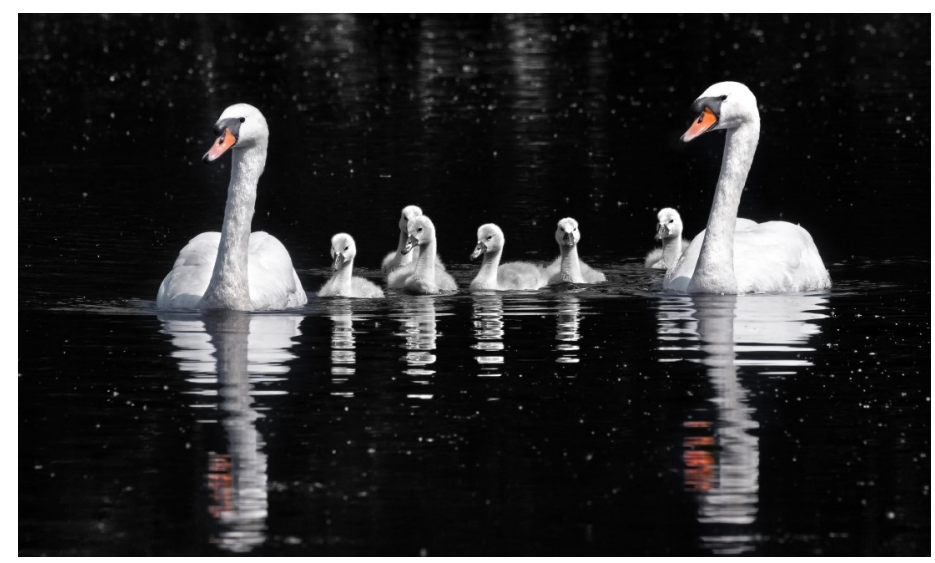

Figure 7. Mute swans with cygnets.

\section{Mortality}

Cygnet mortality rates are relatively unknown due to variations in site characteristics, such as availability of food, density of other mute swans, presence of particularly aggressive mute swans and predators. In one 20-year, mark-recapture study, cygnet mortality was estimated at 60 to 70 percent. Once the mute swans fledged, the mortality rate decreased to about 30 percent for subadults and 10 percent for breeding adults.

\section{Population Status}

Because mute swans are an introduced species and people can purchase and place them (with special permits) on their property, mute swans can be found in many areas of the United States. Feral populations of mute swans occur in three areas of the country: 1) the northeast coast, 2 ) the Great Lakes region, and 3) the northwest coast. Within these areas, mute swans vary in densities from single swans or pairs to over a thousand birds. Several states have developed management plans to reduce the number of feral mute swans breeding in natural habitats to prevent competition with native waterfowl and colonial waterbirds.

\section{Habitat}

Mute swans are found in a variety of habitats with water. Mute swans typically are not afraid of people. They can be found in highly-developed areas, such as densely populated lakes, city parks, subdivisions, airport retention ponds and marinas. As feral populations have grown, however, they have expanded into more natural habitats including lakes, emergent wetlands, rivers and coastal areas of large waters (e.g., the Great Lakes and Chesapeake Bay).

\section{Behavior}

Mute swans are primarily diurnal and feed almost exclusively on submerged aquatic vegetation. In times of stress when food is limited, mute swans have been documented feeding on small fish. 
Mute swans are non-migratory, but they do make local flights during different seasons (Figure 8). During winter in the northern climates, mute swans fly to areas with open water and often gather in large concentrations. When the ice starts to thaw, the swans return to their breeding sites. Breeding adults remain at these sites until the fall when their cygnets are old enough to fly and fend for themselves. Non-breeding sub-adults disperse in the spring to sites with suitable habitat. This may be their birth site or a new area, depending upon the aggressiveness of adult birds in the area. Non-breeding sub-adults undergo a molt in mid to late summer (July to August) and typically migrate to larger bodies of water. Breeding adults remain with their cygnets and molt at breeding sites.

\section{Food Habits}

Mute swans eat throughout the day, from sunrise to shortly after sunset. The main food source of mute swans is submerged aquatic vegetation (Figure 9). They also consume small fish, insects and other small animals incidentally along with plants and when plants are sparse. They prefer shallow waters where they can reach the bottom.

Because of their long necks, mute swans can exploit areas in far deeper water than geese and dabbling ducks. Mute swans use their feet while feeding to expose plant rhizomes and to help dislodge food for cygnets. In one study, mute swans consumed less than 50 percent of what they removed.

During winter in northern climates, mute swans congregate in areas of open water and may feed exclusively on small fish or algae if submerged aquatic vegetation is lacking. In the U.S., mute swans rarely feed on land. When they do, they may feed on crops or grasslands near shores.

In areas with human development, mute swans readily habituate to artificial feeding. Begging behavior becomes more prevalent when aquatic vegetation is limited. Artificial feeding has been responsible for maintaining populations in British Columbia and Traverse City, Michigan.

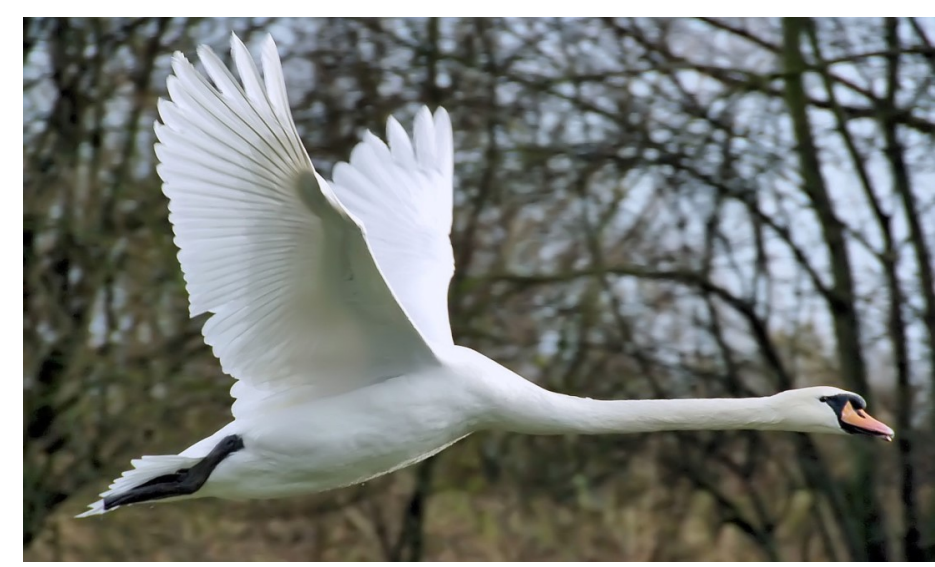

Figure 8. Mute swan in flight.

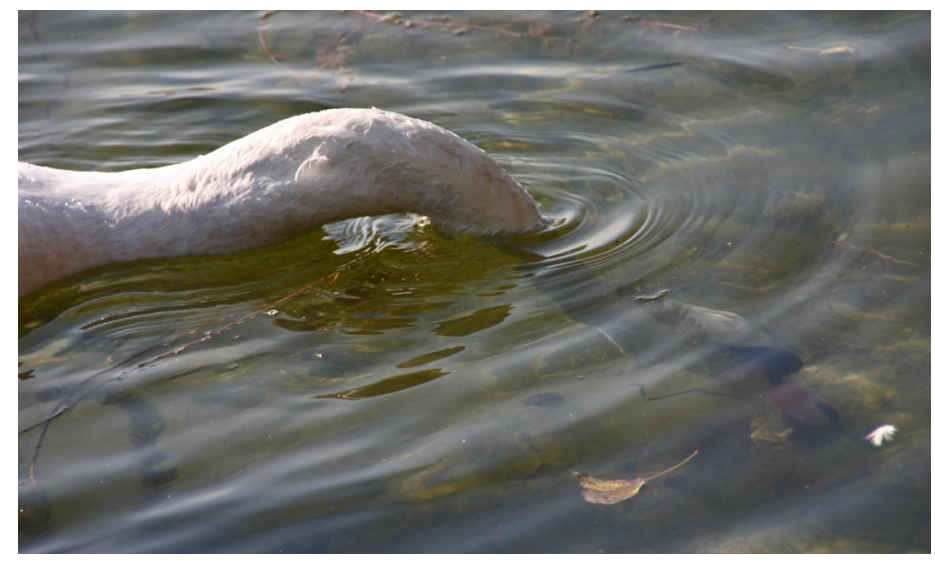

Figure 9. Mute swan feeding on aquatic vegetation and insects.

\section{Legal Status}

Some have questioned the status of mute swans as an introduced species, but multiple reviews by scientists and the U.S. Fish and Wild life Service clearly support the conclusion that mute swans are not native to North America. The Migratory Bird Treaty Act, therefore, does not protect mute swans, and management authority falls under jurisdiction of the states and Tribes.

Before initiating any damage management actions, consult the state wildlife agency regarding the status of mute swans in your area. Management options may be limited and special permits may be required. 


\section{Acknowledgements}

Figure 1. Photo by USDA

Figure 2. Photo by Wikimedia Commons

Figure 3. Photo by Friends of the Detroit River

Figure 4. Photo by Michigan Department of Natural Resources

Figure 5. Graphic by Trumpeter Swan Society

Figure 6. Map by The Birds of North America Online (A. Poole, Ed.). Ithaca: Cornell Lab of Ornithology

Figure 7. Photo by Wikimedia Commons

Figure 8. Photo by Wikimedia Commons

Figure 9. Photo by Wikimedia Commons

Special thanks to Dusty Arsnoe, Jason Suckow, Caleb Wellman for their critical review.

\section{Glossary}

Aviculture: The breeding and rearing of birds.

Bird strike: The collision between a bird or flock of birds and an airplane.

Cygnet: A young swan.

Diurnal: Active during the day.

Effigy: An artificial likeness.

\section{Key Words}

Aggressive birds, Cygnet, Cygnus olor, Invasive species, Mute swan, Waterfowl

\section{Disclaimer}

Wildlife can threaten the health and safety of you and others in the area. Use of damage prevention and control methods also may pose risks to humans, pets, livestock, other non-target animals, and the environment. Be aware of the risks and take steps to reduce or eliminate those risks.

Some methods mentioned in this document may not be legal, permitted, or appropriate in your area. Read and follow all pesticide label recommendations and local requirements. Check with personnel from your state wildlife agency and local officials to determine if methods are acceptable and allowed.

Mention of any products, trademarks, or brand names does not constitute endorsement, nor does omission constitute criticism.

\section{Citation}

Marks, D.R. 2018. Mute Swans. Wildlife Damage Management Technical Series. USDA, APHIS, WS National Wildlife Research Center. Fort Collins, Colorado. 14p. 


\section{Resources}

Ciaranca, M., C.C. Allin, and G.S. Jones. 1997. Mute Swan (Cygnus olor). Pages 273-300 in A. Poole and F. Bill, editors. The Birds of North America, No. 273. The Academy of Natural Sciences, Philadelphia, Pennsylvania and The American Ornithologists' Union, Washington, D.C.

Cornell Lab of Ornithology - All about birds: Mute swan. http://www.allaboutbirds.org/guide/mute_swan/id.

Ellis, M.M. and C.S. Elphick. 2007. Using a stochastic model to examine the ecological, economic and ethical consequences of population control in a charismatic invasive species: Mute swans in North America. Journal of Applied Ecology 44:312-322.

Frequently Asked Questions about Mute Swans. http://www.michigan.gov/dnr/0,4570,7-153-

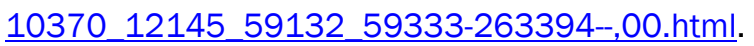

Maryland Department of Natural Resources. 2003. Mute swans in Maryland: A statewide management plan. Maryland Department of Natural Resources Wildlife and Heritage Service.

http://dnr.maryland.gov/wildlife/Documents/MuteSwan_StatewideMgtPlan.pdf.

Michigan Department of Natural Resources. 2012. Mute Swan management and control program policy and procedures. https://www.michigan.gov/documents/dnr/2012 Mute Swan_Policy 378701 7.pdf.

Mississippi Flyway Council. 2012. Mississippi Flyway Council Policy - Management of Mute Swans. Mississippi Flyway Technical Section. https://www.michigan.gov/documents/dnr/ Mississippi Flyway Council Mute Swan policy 364885 7.pdf.

Mute swans in Maryland. http://dnr.maryland.gov/wildlife/Pages/plants wildlife/Invasives/inv MuteSwan.aspx.

Mute swans in Michigan. http://www.michigan.gov/muteswans.

Pedersen, K., D.R. Marks, D.M. Arsnoe, S.N. Bevins, E. Wang, S.C. Weaver, R. M. Mickley, and T.J. DeLiberto. 2014. Short Report: Antibody prevalence of select arboviruses in Mute Swans (Cygnus olor) in the Great Lakes region and Atlantic coast of the United States. The American Journal of Tropical Medicine and Hygiene 91(6):1247-1249. doi: 10.4269/ ajtmh.14-0280.

United States Department of Agriculture Wildlife Services. 2012. Final Environmental Assessment: Mute Swan Damage Management in Michigan. http://www.aphis.usda.gov/regulations/pdfs/nepa/Mute\%20Swan\%20EA\%20Final\%209-2712.pdf. 


\section{Appendix}

Damage Management Methods for Mute Swans

\begin{tabular}{l|l}
\hline Type of Control & Available Management Options \\
\hline Exclusion & $\bullet \quad \begin{array}{l}\text { Install fencing or other barriers along shoreline, around ponds and yards to prevent access } \\
\text { Install overhead wire grids or netting on ponds }\end{array}$
\end{tabular}

Fertility Control None available

Frightening Devices - Pyrotechnics and propane cannons

- Mylar® tape, flags, balloons and effigies

- Dogs or human presence in an area

Habitat Modification - Modify shoreline habitat to impede movement onto land

- Remove vegetation used for nesting and feeding

- Allow ponds and lakes to freeze in winter

Nest Treatment

Allowed with proper State permits; Egg oiling or puncturing of eggshells and nest destruction

Repellents Methyl anthranilate

Shooting Allowed with proper State permits or hunting licenses

Toxicants None available

Trapping Allowed with proper State permits; Live-trapping with rocket or cannon nets, swim-in funnel traps, net guns or by hand 